\title{
Application of natural and enhanced natural attenuation of heavy metals in soils and sediments
}

\author{
Catherine N. Mulligan ${ }^{\text {i) }}$ and Masoumeh Javid ${ }^{\text {ii) }}$ \\ i) Professor, Department of Building, Civil and Environmental Engineering, Concordia University, 1455 de Maisonneuve Blvd. W, \\ Montreal, QC, H3G 1M8, Canada. \\ ii) Ph. D candidate, Department of Building, Civil and Environmental Engineering, Concordia University, 1455 de Maisonneuve Blvd- \\ W, Montreal, QC, H3G 1M8, Canada.
}

\begin{abstract}
Various techniques can be considered for the remediation of contaminated sediments. The options can include capping, dredging, or physical, biological, and/or chemical treatments and natural recovery. Natural recovery could be beneficial over dredging due to a reduction in costs and lack of solid disposal requirements. Source control, however, is a major issue for sustainable remediation. In a case study, surface and core sediment samples were collected from a harbor on the north bank of the St. Lawrence River in the province of Quebec to assess heavy metal pollution and determine if natural recovery was occurring. Comparing the results of all analysis done for sediment for three different years $(2015,2017$ and 2019) in the sampling area, it can be seen that some metals increased, some decreased and some of them showed nearly the same level of contamination. The results also indicated that during the sampling periods, copper, zinc and chromium were the main elements that exceeded the occasional effect level based on the Environment Canada sediment quality guidelines. Therefore, metal pollution has become a noticeable problem in this area and natural recovery was not achieved for several metals due to ongoing contamination and thus source control is critical.
\end{abstract}

Keywords: natural attenuation, natural recovery, heavy metals, harbors, contaminated sediments

\section{INTRODUCTION}

Heavy metal contamination has gradually become a common and important concern world-wide. The distribution of heavy metals in the aquatic environment is as follows: sedimentary phases, suspended forms, colloids and water-soluble species. Major sources include surface runoff, wastewater effluents and discharges, leaks and spills. Sediments are part of the hydrological cycle in which particulate material is transported from land to water bodies. It has been stated that in some conditions, more than $99 \%$ of heavy metals entering a river can be stored in river sediments in different forms ( $\mathrm{Li}$ et al., 2000; Peng et al., 2009). Heavy metals are an important category of pollutants as they can have significant harmful effects on both human health and the health of terrestrial and aquatic communities and ecosystems (Boyd, 2010). A number of heavy metals have been commonly studied as pollutants due to high environmental concern, such as $\mathrm{Cd}, \mathrm{Cu}, \mathrm{Cr}, \mathrm{Hg}, \mathrm{Pb}, \mathrm{Ni}$, and $\mathrm{Zn}$ (Boyd, 2010). It has been reported that the long-term effect on human health is the result of exposure to these pollutants (Khan et al., 2011).

Various natural processes can enable the reduction in the concentration and toxicity of contaminants. These processes are labelled as natural attenuation for groundwater. However, much less attention has been paid to soils and sediment remediation via physical, chemical and biological processes. According to the American Society for Testing and Materials (ASTM) (1998) natural attenuation is the "reduction in mass or concentration of a compound in groundwater over time or distance from the source of constituents of concern due to naturally occurring physical, chemical, and biological processes, such as; biodegradation, dispersion, dilution, adsorption, and volatilization." The US EPA (1999) employs monitored natural attenuation which is: "the reliance on natural attenuation processes (within the context of a carefully controlled and monitored site cleanup approach) to achieve sitespecific remediation objectives within a time frame that is reasonable compared to that offered by other more active methods. The 'natural attenuation processes' that are at work in such a remediation approach include a variety of physical, chemical, or biological processes that, under favorable conditions, act without human intervention to reduce the mass, toxicity, mobility, volume, or concentration of contaminants in soil or groundwater. These in-situ processes include biodegradation; dispersion; dilution; sorption; volatilization; radioactive decay; and chemical or biological stabilization, transformation, or destruction of contaminants." 
For sediments, sediment-water partitioning can release contaminants into the pore water and to benthic organisms (Mulligan et al., 2010). The mechanisms need to be understood to establish protocols for natural attenuation. Some of the factors influencing natural attenuation in sediments include organic and salt contents, mixing energy and suspended solid deposition.

For sediment remediation, dredging, capping or other treatments are employed. Natural attenuation of contaminants, also known as natural recovery, can be more cost-effective than these methods. According to the USEPA (1994), however, it cannot be used if "contamination poses severe and substantial risks to aquatic life, wildlife and human health. It may not be the method of choice for contaminants that biodegrade or transform into more persistent, toxic compounds".

Monitoring is essential for evaluation of the feasibility of natural recovery and achievement of the remediation objectives for sediments. The mechanisms are summarized in Fig. 1. Transformative mechanisms are more dominant in natural attenuation, whereas isolation and mixing can prevail in sediments. Thus, the term monitored natural recovery (MNR) is used.

The NRC (2007) defined MNR as "leaving contaminated sediments in place". This enables various aquatic, biological and sedimentation processes to reduce contaminant bioavailability. The USEPA (2005) indicates that in addition to reducing bioavailability, toxicity is also reduced. It views MNR as a mature technology. While it can be difficult to convince regulatory bodies and the public to accept MNR as the contaminants are not removed from the site, acceptance is increasing due to the increasing remediation costs for alternatives.

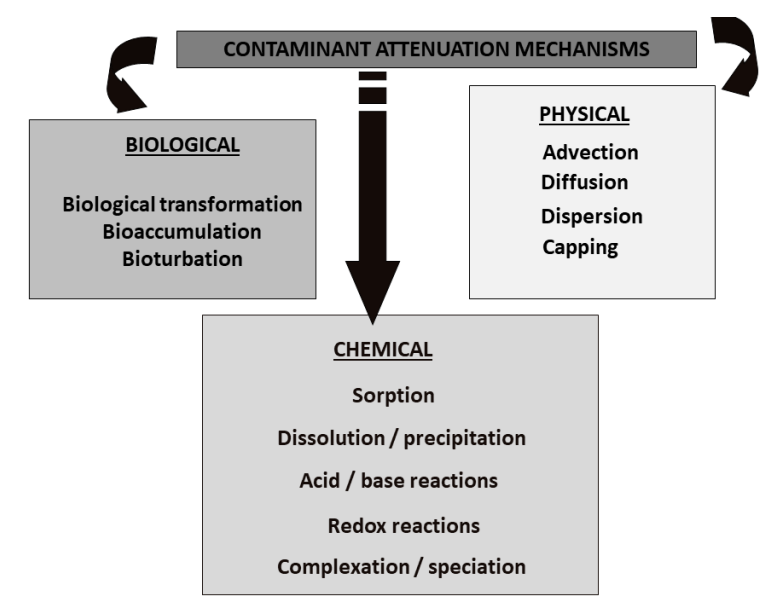

Fig. 1. Mechanisms of natural recovery (adapted from Yong and Mulligan, 2019).

\section{NATURAL RECOVERY PROCESSES}

According to the NRC (1997), MNR involves various aquatic, sedimentary and biological mechanisms. Transformation processes can convert contaminants to less toxic forms, whereas sorption and reduces the mobility and bioavailability of contaminants. Metal sulfides can form under anaerobic conditions which reduces their solubility and risk to organisms.

Particle dispersion, and diffusive/advective transport can release contaminants. Contaminants also can be transported to the sediment surface by bioturbation and gas ebullition from organic matter degradation can bring potential subsequent release. The rate of bioturbation has been shown to be a significant form of contaminant release coefficient $\left(\mathrm{k}_{\mathrm{eff}}\right)$ of $1 \mathrm{~cm} / \mathrm{yr}$ compared to gas ebullition $(0.0033 \mathrm{~cm} / \mathrm{yr})$ (Reible, 2006).

Natural capping is also significant and is comprised of the overlay of clean sediments over contaminated sediments (Cardenas and Lick, 1996), thus reducing bioaccumulation and toxicity. Sediment deposit rates, resuspension and erosion will thus determine the rate of attenuation. The rate of clean newly deposited sediments must be higher than resuspension and erosion rates.

In addition, sedimenting particles can adsorb contaminants which can be obtained from urban and agricultural runoffs. These contaminants can thus slow the remediation process. Propeller wash, waves and even the benthic community may resuspend sediments. Thus, covered contaminated sediments may become exposed. Bioturbation occurs when the benthic community travels through the sediments or enhances the pore water exchange rate by transporting contaminated sediments to the surface. Oxidation of heavy metal sulfides can release the heavy metals from previously anaerobic sediments (USEPA, 1995). Contaminated sediments can also be transported by river floods (Cardenas et al., 1995) and large storms (Lick et al., 1994).

\subsection{Evaluation of the natural recovery of sediments}

To evaluate natural recovery, the sedimentcontaminant interactions and environmental conditions must be understood. Although there is excellent potential, there is much less information regarding the natural attenuation of heavy metal contaminants than for organic chemicals. While dredging, is one of the main remediation techniques for sediments, it can increase oxidation, leading to increased solubility, mobility and bioavailability of heavy metals (cadmium, copper, lead, mercury, nickel, and zinc) (Darby et al., 1986). As ecological sensitive areas are potentially at risk during dredging operation, natural recovery may be more suitable.

Some environmental conditions such as storms, water flows and currents in surface water can potentially lead to the mobilization of contaminants. They can increase mixing and resuspension of sediments, and subsequently the dilution, and diffusion 
of contaminants. Bioturbation can cause particle mixing and solute transport which can also influence pollutant movement. The characterization, presence and distribution of the biota and their mechanisms of bioturbation must be determined to predict the contaminant behavior (Banta and Andersen, 2003). Prediction of the sedimentation rates and contaminant fluxes can be highly uncertain for determining the effectiveness of natural capping.

Other factors such as $\mathrm{pH}$, oxidative/reduction conditions, complexation, and microbial species changes can influence the mechanisms of sorption, sedimentation, and mobility. These factors can thus influence the rate of natural recovery. The potential for sediment natural recovery must be determined by multiple lines of evidence (Fig. 2) including:

- Evidence of reduction in exposure and toxicity

- Identification of the primary reduction rates and mechanisms

- Data for future process projection.

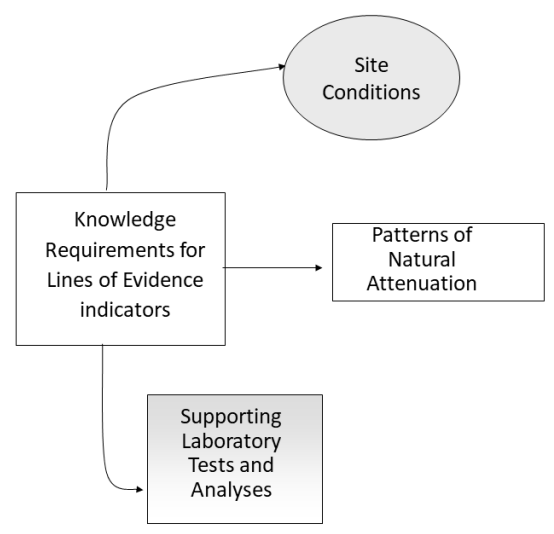

Fig. 2. Lines of evidence for MNR (adapted from Mulligan et al., 2010).

Some methods for evaluating the rates of natural recovery can include grab samples over time, exponential time decay function data and dated sediment cores for determining contaminant transport. A study by Lin et al. (2017) on sediment in Pallanza Bay, Lake Maggiore, Italy employed three techniques. They included sediment traps for determination of quality and deposition rates of sediment under different conditions, sediment cores for evaluating trends in concentrations over time and passive samplers for assessing the mobility of sediment contaminants and release from the sediment. It was the first time the three techniques were employed for determining the mobility of dichlorodiphenyltrichloroethane (DDT) from sediments (Lin et al. 2017). Techniques such as selective sequential extraction can assist in evaluating the potential for heavy metal mobilization. For example, Pourabadehei and Mulligan (2016b) showed that sequential extraction could be used to establish risk assessment and the potential for mobilization of metals to the aqueous phase from sediments in a harbor area. Both sediment and suspended particle matter was evaluated. It was found that lead and cadmium levels, in particular, were in the levels of medium to very highrisk. To evaluate the effectiveness of the natural recovery, reduction of bioavailability, toxicity, and transport of the contaminants must be achieved.

\subsection{Protocols for MNR}

A general protocol for evaluating MNR for contaminated sediments includes determination of site specific data (Fig. 3). To determine if site conditions are suitable, laboratory tests and predictive models can be performed. The RTDF has proposed that the following steps be undertaken (Magar et al., 2004):

- Historical site-specific data review including flood, high wave or tidal influences

- Geomorphology assessment that includes sediment texture and thickness, hydrology/hydrodynamic data, and sediment transport data

- Hydrodynamic measurement and modeling

- Determination of sediment erosion and transport

- Determination of the sediment core chemistry profiles

- Hydrographic characteristic survey.

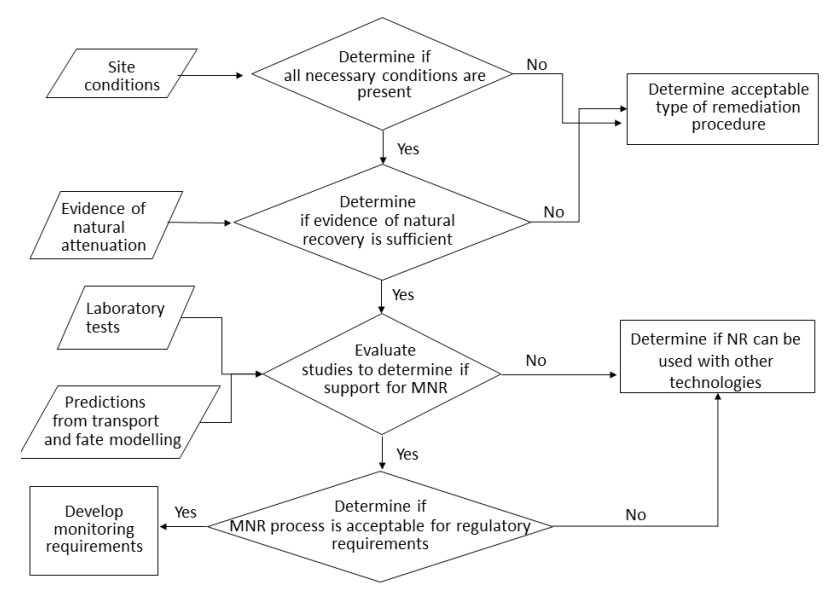

Fig. 3. General protocol for assessment of MNR (adapted from Yong and Mulligan, 2019).

Modelling can be used to evaluate transport and deposition of the sediment. Data can be obtained by sonar, conventional probes and sampling. If the conditions for natural recovery are not appropriate, dredging or capping may be required. Monitoring is integral evaluating MNR. The pollutants both in the water and sediments and environmental conditions $(\mathrm{pH}$, redox changes) need to be monitored. Laboratory tests and models used for prediction can be verified by the monitoring which contributes to the main costs of MNR.

In comparison to engineered remediation 
techniques, MNR may take longer periods of time but can have significant social and environmental benefits. Technologies such as dredging can lead to habitat destruction, and there are limitations on landfilling and other aspects of sediment disposal.

Once all the data is obtained, a weight-of-evidence was suggested by the RTDF (Magar et al., 2004) to balance the findings. The approach included:

- Identification of areas with similar sediment and contaminant characteristics

- Organize the data in a matrix or graphical format

- Formulate conclusions with regards to longterm behavior

- Identify the potential impact of the predictions

- Consider the uncertainties

- Provide conclusions.

If the natural attenuation processes do not achieve the required remediation goals, other remediation options will then need to be employed. The section of the remediation should be based on effectiveness, ability to be implemented and costs. Short-term contaminant releases, risk reduction rate, and long-term risk should also be considered. In general, MNR is very low in risks for short-term releases and treatment magnitude. However, the risk reduction rate can vary between low to high (NRC 1999). Overall, MNR must achieve the remediation objectives in an adequate time with minimal risk to humans and the environment.

A thin layer of sediment or sand can be employed to accelerate concentration reduction and achieve cleanup goals if the rate of MNR is not sufficient. Other materials may also be added such as activated carbon to reduce bioavailability. Due to the sustainability benefits of MNR, it can be integrated into a remediation process. Engineering the natural attenuation capability of sediments, through the use of geochemical, biological and nutrient enhancement, will provide more sustainable management options.

Although initially information was limited for sediments and concentrated mainly on soil/groundwater systems, MNR guidance was established (USEPA 2005). Activities and requirements for MNR are shown in Fig. 4.

Ecological risk assessments are now required more frequently and include Sediment Quality Guidelines (SQG) are used as part of the evaluation. They include aspects such as (Apitz et al., 2005):

- Contamination nature and extent

- Benthic diversity indices of with no contaminants

- Effects of the contaminants on the bioavailability, bioaccumulation, and other organisms

- Fate and transport of the contaminants and sediments Evaluation of the potential risks of the contaminants towards the aquatic biota and

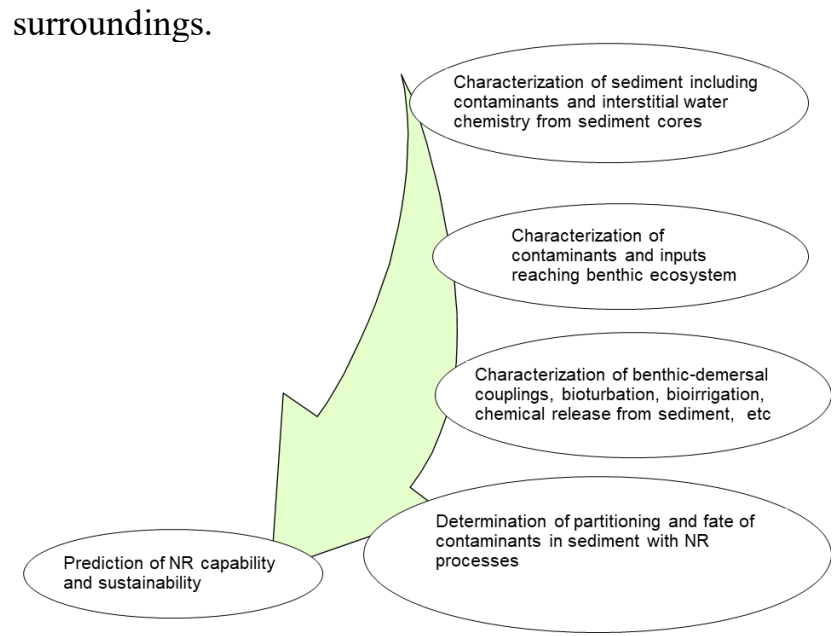

Fig. 4. Evaluation of the sustainability of NR (adapted from Mulligan et al., 2010).

Short- and long-term risks include loss of habitats and aquatic life, and decreased water quality and recreational activities. In the long-term, the risk for contamination reoccurring and the potential for ecosystem recovery needs to be determined. However. monitoring methods need to be developed for quantifying MNR and specific research is needed for various aquatic environments (fresh water, coastal, and marine).

To evaluate natural recovery, various forms of evidence are needed including:

- Natural contaminant burial and deposition of clean sediments

- Evidence of sorption, precipitation, and other processes for reduction of contaminant mobility

- Indication of biological or chemical transformation processes

- Dispersion of particle-bound contaminants to reduce contaminant concentrations.

Available protocols focus on fuel hydrocarbons or chlorinated solvents with little guidance on PAHs, PCBs, explosives, metals, inorganics, and radionuclides. Therefore, there are major shortcomings in these protocols. Few protocols consider soil with the exception of the USEPA (1998) and those by the Department of Energy (DOE). Even fewer focus on sediments. Sediments can be transported and have higher organic contents than soils. Near the sediment surface, oxidizing conditions are present. In marine sediments, sulfate reduction occurs, while in freshwater sediments, methanogenesis can dominate.

To demonstrate that natural recovery is taking place, in sediments, lines of evidence have been developed by the USEPA (2005) including:

- Decreasing contaminant concentration in higher trophic level biota such as fish 
- Decreasing water column concentrations from high biological activity under low flow (summer) conditions

- Decreasing sediment contaminant concentrations in cores over time

- Decreasing trends in surface sediment contaminants and sediment toxicity.

Spatial and temporal sediment characteristics can vary substantially and thus this should be taken into account when evaluating trends. Numerous tools are available for determining MNR mechanisms of sedimentation, contaminant physical, chemical and biological weathering processes and ecosystem impacts and recovery (Yong and Mulligan, 2019).

\section{CASE STUDY}

Harbor areas are economically important around the world. Human activities at the harbor area result in adverse effects on the aquatic environment. Sediments in a harbor area adsorb pollutants that originate from industrial, domestic sewage and wastewater, petroleum and compounds released by antifouling paints. Among the different contaminants in the sediment, heavy metals have been extensively studied due to their mobility and toxicity in the aquatic ecosystem (Pourabadehei and Mulligan, 2016a).

The aim of this study is to determine the mean concentrations of heavy metals including $\mathrm{Cr}, \mathrm{Ni}, \mathrm{Cu}$, $\mathrm{Zn}, \mathrm{As}, \mathrm{Cd}$ and $\mathrm{Pb}$ in sediment from a harbor on the north bank of the St. Lawrence River in the province of Quebec, Canada. The relationships between the metal levels in samples collected from different years and physicochemical parameters were assessed to determine the potential of natural recovery.

The yacht club is located on the bank of the St. Lawrence River. It covers an area of approximately $15,000 \mathrm{~m}^{2}$. The water depth varied between $0.6 \mathrm{~m}$ (around the dock area) and $3 \mathrm{~m}$ (around the floating breakwater). Two floating and one solid breakwater have protected the harbor from the waves. The boat maintenance area was located at the northwest part of the harbor and was mainly used for repair and repainting in the summer and storing the boats in the winter (Pourabadehei and Mulligan, 2016a). The sampling took place in 2017 (ten stations) and 2019 (eight stations). Moreover, these data were compared with 2015 data (fifteen stations). The sampling sites (S1-S15) are shown in Fig. 5. S1-S15 are along the passageways and the dock area, which are the most potential places for dredging. When the water level is low, there is an urgent need to remove the sediments from areas around the dock and passageways in order to facilitate the passage of the larger yachts. It has been almost 15 years since dredging was performed in this harbor (Pourabadehei and Mulligan, 2016a). Furthermore, prior to dredging or any method of management of the sediment, the quality must be assessed to evaluate the viable management options (Pourabadehei and Mulligan, 2016b). Guidelines have been used as interpretive tools in many sediment assessments throughout North America and elsewhere (Long et al., 1998). In this study assessment of the quality of sediment samples was performed according to the guidelines issued by Environment Canada and the Ministère du Développement durable, de l'Environnement et des Parcs (Environment Canada, 2007).

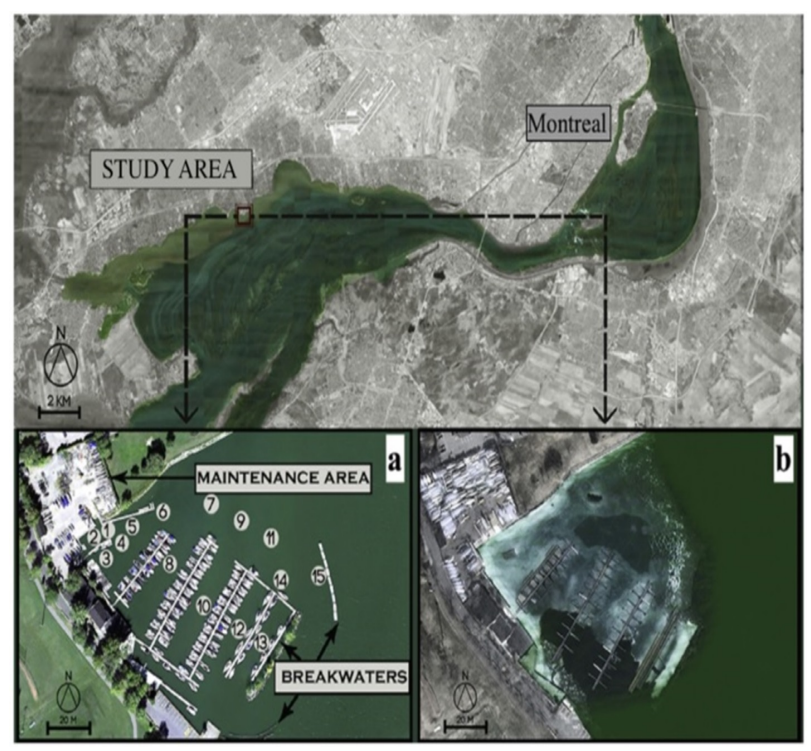

Fig. 5. Study area on the north bank of the St. Lawrence River (Pourabadehei and Mulligan, 2016b). Sample points are shown in insert a.

\section{MATERIALS AND METHODS}

\subsection{Sediment sampling}

At each station, sediment samples were collected with a Birge-Ekman sampler from the surface of the sediments to a maximum depth of $10 \mathrm{~cm}$. Each sample was about $1 \pm 0.2 \mathrm{~kg}$ (wet). Sediment samples were put in polypropylene (PP) bottles and immediately stored in an icebox. Care was taken to avoid any contamination during the transport to laboratory, where they were stored in a $4^{\circ} \mathrm{C}$ refrigerator until further analysis.

\subsection{Core sampling}

The core sediments were compacted and collected in a stainless-steel cylinder with a diameter of $6.3 \mathrm{~cm}$ and a height of $21 \mathrm{~cm}$. Sediment samples were transferred and kept in the airtight poly- ethylene bottles and placed in an ice-cooled box. In total, 6 core sediment samples were obtained from selected stations (Fig. 5). The sediment cores were sectioned into $2 \mathrm{~cm}$ intervals using a thin plastic cutter. The samples were immediately stored in plastic container and then before analysis. 
All plastic- and glassware used during the experiment process were soaked in 5\% (v/v) nitric acid and $2.5 \%(\mathrm{v} / \mathrm{v})$ hydrochloric acid (trace metal grade) for at least $8 \mathrm{~h}$ followed by two rinses with deionized water (prepared using a Milli-Q $18 \mathrm{~m} \Omega \mathrm{cm}$ ). Also, all sediment samples were analyzed using a blank, control and duplicates.

Deionized water (Milli-Q $18 \mu^{\prime} \Omega \mathrm{cm}$ ) was used throughout the study. All glassware and plastic containers used in the experiments were cleaned by soaking in a 5\% $1: 1 \quad \mathrm{HNO}_{3}: \mathrm{HCl}$ mixture acid bath overnight followed by thorough rinsing with deionized water.

\subsection{Sample analysis}

The physical parameters including total organic matter (loss on ignition, LOI) and particle size analysis were analyzed according to the methods described by (Pourabadehei and Mulligan, 2016b). After oven-drying of the sediment to constant weight (usually 12-24 h at ca. $105{ }^{\circ} \mathrm{C}$ ) organic matter was combusted in a temperature between 500 and $550^{\circ} \mathrm{C}$ for $4 \mathrm{~h}$. The LOI is then calculated using the following equation:

LOI $\left.\%=\left(\left(\mathrm{W} 105^{\circ} \mathrm{C}-\mathrm{W} 550^{\circ} \mathrm{C}\right) / \mathrm{W} 105^{\circ} \mathrm{C}\right)\right) * 100$

Analysis of the particle size distribution of sediment samples was done by a laser scattering analyzer (HORIBA, LA-950V2). D50 (50\% of the particles are less than this size) and the percentage of clay, silt and sand for each sample was determined.

Analysis of trace metals was conducted on sediments after complete dissolution using $\mathrm{HNO}_{3}, \mathrm{HCl}$ acids and $\mathrm{H}_{2} \mathrm{O}_{2}$. The EPA $3050 \mathrm{~B}$ method was the protocol used to digest the solid samples and prepare them for using in ICP-MS (U.S. Environmental Protection Agency, 1996). The concentrations of heavy metals and metalloids were determined by Inductively Coupled Plasma Mass Spectrometry (ICP-MS, Agilent 7700x).

\subsection{Sediment quality guidelines}

Three guideline values, Occasional Effect Level (OEL), Frequent effect Level (FEL) and Threshold Effect Level (TEL) were developed as an evaluation for the level of contamination for the management of dredged sediment (Environment Canada 2007). The TEL represents the upper limit of the range of sediment chemical concentrations that is dominated by no-effect data entries. In this range of concentrations of sediment-associated, chemicals are not considered to represent significant hazards to aquatic organisms.

The OEL and FEL are to be used for management of dredged sediment disposal and remediation decisions. For substances above the OEL, adverse effects are anticipated in many benthic species. Sediments containing elements exceeding FEL are contaminated and the site must be treated before any action. Adverse effects are expected for the majority of benthic species. Table 1 shows the criteria for evaluating the quality of sediment samples for heavy metals.

Table 1. Environment Canada (2007) criteria for the assessment of sediment quality $(\mathrm{mg} / \mathrm{kg})$.

\begin{tabular}{llllllll}
\hline Level & $\mathrm{Cr}$ & $\mathrm{Ni}$ & $\mathrm{Cu}$ & $\mathrm{Zn}$ & $\mathrm{As}$ & $\mathrm{Cd}$ & $\mathrm{Pb}$ \\
\hline TEL & 37 & - & 36 & 120 & 6 & 0.6 & 35 \\
\hline OEL & 57 & 47 & 63 & 170 & 8 & 1.7 & 52 \\
\hline FEL & 120 & - & 700 & 770 & 23 & 12 & 150 \\
\hline
\end{tabular}

\section{RESULTS AND DISCUSSION}

\subsection{Physical characteristics of sediment samples}

Physical characteristics including $\mathrm{D}_{50}$, particle size distribution and organic matter are presented in Tables 2 and 3 in years 2017 and 2019 respectively. Several sediment samples represent a relatively high organic (high LOI). The average median particle size of the sediment was found to be $45 \mu \mathrm{m}$ (2017) and $95 \mu \mathrm{m}$ (2019), which was higher than the $1.33 \mu \mathrm{m}$ reported previously for this area (Pourabadehei and Mulligan, 2016a). The results showed that texture of sediment at stations 1,2 and 3 were significantly coarser than the other stations. This agrees with previous studies that noted that station 1 is coarser which is the entrance of the maintenance boat area to the harbor.

\subsection{Total content of metals}

Tables 4 and 5 present the concentrations of heavy metals ( $\mathrm{Cr}, \mathrm{Pb}, \mathrm{Cd}, \mathrm{As}, \mathrm{Cu}, \mathrm{Zn}$ and $\mathrm{Ni}$ ) in a 2017 and 2019 study. Among the different stations, the bold numbers are the concentrations of elements exceeding the OEL. The results show that all concentrations were below the FEL. This was especially true for the cases of $\mathrm{Cr}, \mathrm{Cu}$ and $\mathrm{Zn}$, which were more than the guideline values in most of the stations in both 2017 and 2019 . Thus, the sediment samples can be categorized as contaminated sediment, which need to be managed (Pourabadehei and Mulligan, 2016c). Furthermore, frequent monitoring and additional health risk assessments are necessary for metal levels above the upper limits in the future.

The results of metal concentrations demonstrate that some metals including $\mathrm{Zn}, \mathrm{Cr}$ and $\mathrm{Cu}$ are the main contaminants detected in the sediment samples. Copper, zinc, cadmium and lead are the most common components of many antifouling paint formulations. Therefore, these contaminants $(\mathrm{Zn}, \mathrm{Cr}, \mathrm{Ni}$ and $\mathrm{Cu})$ are mainly associated with the antifouling paint.

From these results, it is observed that some of the heavy metal concentrations $(\mathrm{Cr}, \mathrm{Pb}$ and $\mathrm{Zn}$ ) have decreased when compared with the previous study in 2015 (Table 6). The mean concentrations of $\mathrm{Cd}$ and As were approximately to the same as the findings of the previous study in 2015 .

\subsection{Assessment of heavy metals in sediment}

In the interpretation of assessment of heavy metals in the sediment, the choice of comparing the concentration of heavy metals with the background levels plays an important role. Several researchers have used the 
background level (Environment Canada,1993) observed prior to industrialization data as reference baselines.

Table 2. Physical characteristics of sediment samples (2017).

\begin{tabular}{cccccc}
\hline $\begin{array}{c}\text { St. } \\
\text { No }\end{array}$ & LOI\% & $\begin{array}{c}\text { D }_{50} \\
(\mu \mathrm{m})\end{array}$ & Clay & $\begin{array}{c}\text { Silt } \\
(\%)\end{array}$ & Sand \\
\hline 2 & 17.0 & 53 & 4.21 & 50.57 & 45.21 \\
\hline 3 & 11.4 & 43 & 4.06 & 54.18 & 34.8 \\
\hline 5 & 15.7 & 94 & 2.45 & 43.9 & 53.75 \\
\hline 7 & 2.78 & 138 & 4.16 & 43.49 & 52.35 \\
\hline 8 & 11.3 & 26 & 6.85 & 73.4 & 19.75 \\
\hline 10 & 9.1 & 16.5 & 9.29 & 72.2 & 8.38 \\
\hline 12 & 9.4 & 17 & 9.10 & 72.22 & 18.68 \\
\hline 13 & 9.4 & 6.6 & 7.47 & 75.67 & 15.75 \\
\hline 14 & 9.6 & 23 & 7.31 & 67.62 & 25.07 \\
\hline 15 & 6.1 & 42 & 5.56 & 65.64 & 28.79 \\
\hline
\end{tabular}

Table 3. Physical characteristics of sediment samples (2019).

\begin{tabular}{cccccc}
\hline $\begin{array}{c}\text { St. } \\
\text { No }\end{array}$ & LOI\% & $\begin{array}{c}\text { D }_{50} \\
(\mu \mathrm{m})\end{array}$ & Clay & Silt $(\%)$ & Sand \\
\hline 1 & 9.2 & 252 & 1.45 & 28.32 & 70.22 \\
\hline 3 & 14.3 & 279 & 1.15 & 28.80 & 70.03 \\
\hline 4 & 14.9 & 65 & 4.55 & 59.37 & 36.07 \\
\hline 6 & 5.9 & 51 & 11.62 & 56.45 & 31.91 \\
\hline 8 & 11.1 & 25 & 14 & 64.60 & 21.40 \\
\hline 9 & 15.6 & 73 & 9.38 & 57.13 & 33.48 \\
\hline 11 & 10.8 & 14 & 21.17 & 59.84 & 18.97 \\
\hline 14 & 9.3 & 6.5 & 46.72 & 40.19 & 7.14 \\
\hline
\end{tabular}

Table 4. Total concentration of heavy metals in sediment samples in 2017 (mg/kg).

\begin{tabular}{clllllll}
\hline St. No & $\mathrm{Cr}$ & $\mathrm{Ni}$ & $\mathrm{Cu}$ & $\mathrm{Zn}$ & $\mathrm{As}$ & $\mathrm{Cd}$ & $\mathrm{Pb}$ \\
\hline 2 & $\mathbf{7 1 . 1}$ & 38.5 & $\mathbf{2 2 2 . 6}$ & $\mathbf{2 5 6 . 7}$ & 6.4 & 0.7 & 48.6 \\
\hline 3 & $\mathbf{7 2 . 7}$ & 37.3 & $\mathbf{7 9 . 9}$ & $\mathbf{1 9 7}$ & 7.8 & 0.7 & 44.3 \\
\hline 5 & 50.5 & 30.6 & $\mathbf{7 3}$ & 166.5 & 4.9 & 0.6 & 29.3 \\
\hline 7 & 25.2 & 14.7 & 15.8 & 36.9 & 2.6 & 0.6 & 12.5 \\
\hline 8 & $\mathbf{7 4 . 4}$ & $\mathbf{4 9 . 9}$ & 43 & $\mathbf{1 8 3 . 8}$ & 5.8 & 0.7 & 30.9 \\
\hline 10 & $\mathbf{7 5 . 2}$ & 75.2 & 52.1 & $\mathbf{1 8 9 . 5}$ & 6.1 & 0.76 & 32.8 \\
\hline 12 & $\mathbf{7 7 . 9}$ & 45.1 & 53.2 & 53.2 & 5 & 0.8 & 35.1 \\
\hline 13 & $\mathbf{7 9 . 9}$ & 45 & 46.4 & $\mathbf{1 9 4 . 9}$ & 4.9 & 0.7 & 29.9 \\
\hline 14 & $\mathbf{7 0 . 5}$ & 41.4 & 49.6 & $\mathbf{1 7 9 . 2}$ & 5.9 & 0.8 & 33.1 \\
\hline 15 & 56.5 & 29.7 & 38.9 & 150.7 & 6.3 & 0.9 & 31.8 \\
\hline
\end{tabular}

Table 5. Total concentration of heavy metals in sediment samples in $2019(\mathrm{mg} / \mathrm{kg})$.

\begin{tabular}{clllllll}
\hline St. No & $\mathrm{Cr}$ & $\mathrm{Ni}$ & $\mathrm{Cu}$ & $\mathrm{Zn}$ & $\mathrm{As}$ & $\mathrm{Cd}$ & $\mathrm{Pb}$ \\
\hline 1 & 54.5 & 28.3 & $\mathbf{4 5 0 . 3}$ & $\mathbf{2 3 0 . 1}$ & 7.0 & 0.72 & $\mathbf{5 7 . 0}$ \\
\hline 3 & $\mathbf{6 1 . 1}$ & 32.6 & $\mathbf{1 6 5 . 9}$ & $\mathbf{2 4 4 . 1}$ & $\mathbf{8 . 1 2}$ & 0.74 & $\mathbf{5 5 . 3}$ \\
\hline 4 & $\mathbf{6 2 . 9}$ & 32.0 & $\mathbf{1 3 6 . 6}$ & $\mathbf{2 9 7 . 0}$ & 7.0 & 0.92 & 46.9 \\
\hline 6 & 31.09 & 19.4 & 24.6 & 97.6 & 4.0 & 0.35 & 18.3 \\
\hline 8 & $\mathbf{6 1 . 1}$ & 35.4 & 50.3 & $\mathbf{2 4 1 . 4}$ & 6.9 & 0.74 & 28.8 \\
\hline 9 & $\mathbf{6 8 . 9}$ & 36.4 & 49.0 & $\mathbf{2 1 2 . 4}$ & 7.7 & 0.82 & 32.7 \\
\hline 11 & $\mathbf{6 4 . 2}$ & 34.9 & 51.10 & $\mathbf{2 0 5 . 8}$ & 6.5 & 0.74 & 28.9 \\
\hline 14 & $\mathbf{7 4 . 7}$ & 41.8 & $\mathbf{1 0 9 . 5}$ & $\mathbf{2 1 2 . 8}$ & $\mathbf{9 . 9}$ & 0.77 & 32.8 \\
\hline
\end{tabular}

Table 6. Mean concentration of heavy metals in sediment samples in 2015, 2017 and $2019(\mathrm{mg} / \mathrm{kg})$.

\begin{tabular}{cccccccc}
\hline Year & $\mathrm{Cr}$ & $\mathrm{Ni}$ & $\mathrm{Cu}$ & $\mathrm{Zn}$ & $\mathrm{As}$ & $\mathrm{Cd}$ & $\mathrm{Pb}$ \\
\hline $2015^{*}$ & 66.1 & 40.2 & 95.2 & 251.4 & 7.8 & 0.82 & 50.2 \\
\hline 2017 & 65.4 & 40.7 & 67.5 & 160.8 & 5.6 & 0.73 & 32.8 \\
\hline 2019 & 59.8 & 32.6 & 129.7 & 217.7 & 7.1 & 0.73 & 37.6 \\
\hline
\end{tabular}

*(Pourabadehei and Mulligan, 2016b).

Table 7. Natural levels of selected heavy metals and metalloids in pre-industrial sediment in the St. Lawrence River $(\mathrm{mg} / \mathrm{kg})$.

\begin{tabular}{cccccccc}
\hline & $\mathrm{Cr}$ & $\mathrm{Ni}$ & $\mathrm{Cu}$ & $\mathrm{Zn}$ & $\mathrm{As}$ & $\mathrm{Cd}$ & $\mathrm{Pb}$ \\
\hline Natural level & 60 & 29 & 19 & 86 & 7 & 0.2 & 13 \\
\hline
\end{tabular}

In order to compare the concentrations of heavy metals with their background, exceeding levels were calculated using the equation,

$$
\text { Exceeding level } \%=((\mathrm{Mml}-\mathrm{Mnl}) / \mathrm{Mml}) * 100
$$

where, $\mathrm{Mml}$ is the measured concentration of the heavy metals and Mnl is the natural level of the heavy metals in pre-industrial sediment.

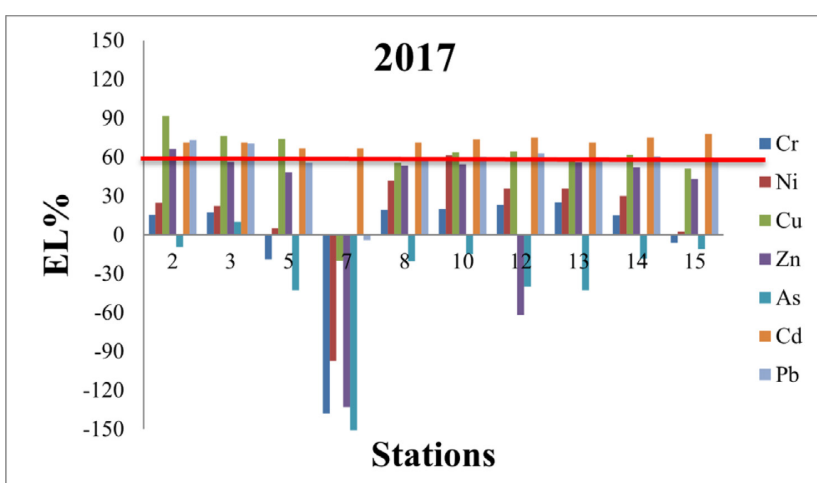

Fig. 6. EL for selected heavy metals in all sediment samples (2017) (red horizontal line shows $\mathrm{EL}=60 \%$ ).

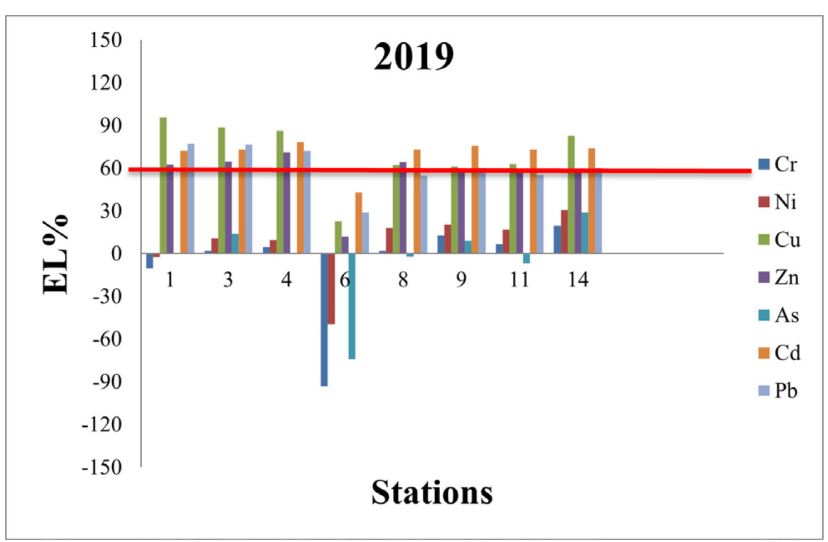

Fig. 7. EL for selected heavy metals in all sediment samples (2019) (red horizontal line shows EL=60\%).

Samples with significant exceeding levels were considered as pollutants. Figs. 6 and 7 show the EL for selected heavy metals in all stations in 2017 and 2019 respectively. $\mathrm{Cu}, \mathrm{Zn}, \mathrm{Cd}$ and $\mathrm{Pb}$ are the heavy metals 
that were exceeded by more than $60 \%$ of their natural levels (NL) in both 2017 and 2019 in almost all stations. As a whole, concentrations of most of the metals exceeded some well recognized standard values and are in agreement with some previous studies (Table 6),(Pourabadehei and Mulligan, 2016c).

\subsection{Variation in total concentration of heavy metals with sediment depth}

Fig. 7 (a) and (b) show the variations in heavy metal levels with different sediment depths of two sediment cores. $\mathrm{Cr}$ and $\mathrm{Mn}$ in all stations tended to increase with an increase in sediment depth. This indicates that sediment deposits were cleaner than in the past. The total concentration of $\mathrm{Ni}$ did not vary with different sediment depths for station 6. However, the $\mathrm{Ni}$ concentration gradually increases from the surface with increasing the depth in station 1 . The $\mathrm{Cu}$ concentration in S6 varied with depth, and has a value of $87 \mathrm{mg} / \mathrm{kg}$ at a depth of $0-2 \mathrm{~cm}$. However, the concentration of copper at the deepest sediment was $71 \mathrm{mg} / \mathrm{kg}$. The total concentration of $\mathrm{Cu}$ in station 1 tended to decrease with an increase in sediment depth. Arsenic concentration did not change significantly in station 6 with an increase in sediment depth and has a maximum value of $10 \mathrm{mg} / \mathrm{kg}$ in the core fraction at a depth of 16-20 cm from the surface. The total concentration of cadmium in station 6 tended to increase with an increase in sediment depth. The concentration of cadmium varied with depth, has a maximum value of $0.9 \mathrm{mg} / \mathrm{kg}$ at a depth of 18-20 cm from the surface in stations 1 . The concentration of lead varied with depth, has a maximum value of $87 \mathrm{mg} / \mathrm{kg}$ at a depth of $18-20 \mathrm{~cm}$ from the surface in station 1 . $\mathrm{Pb}$ concentrations fluctuated in station 6 with a maximum value of 221 $\mathrm{mg} / \mathrm{kg}$ at a depth of $14-16 \mathrm{~cm}$ from the surface.

a

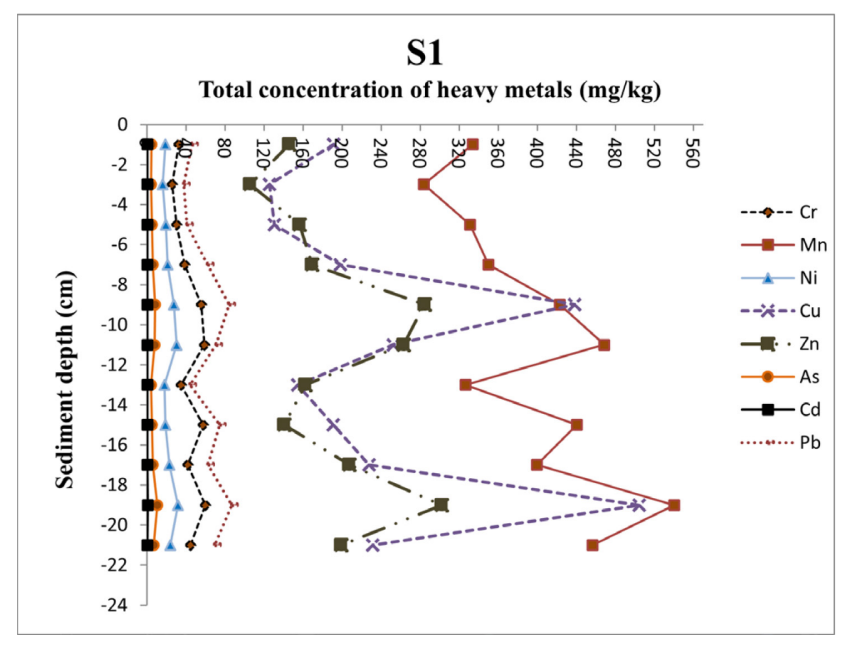

b

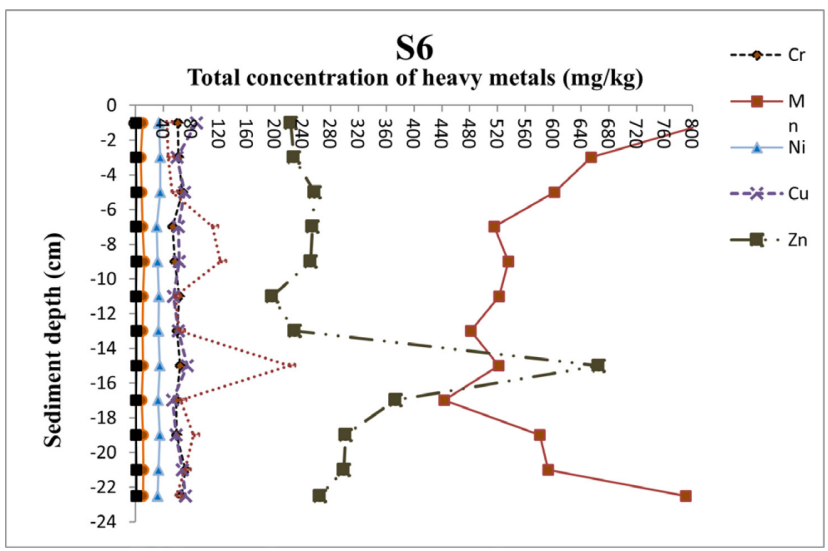

Fig. 7. Variations in total concentration of heavy metals with different sediment depths in stations S1 (a) and S6 (b).

\section{CONCLUSIONS}

In the present investigation concentrations of $\mathrm{Cr}, \mathrm{Cu}$ and $\mathrm{Zn}$ were higher than the safe recommended values, which suggested that the harbor is polluted by heavy metals and might create an adverse effect on this area. The overall pollution load has not significantly changed in 2015, 2017 and 2019, indicating that natural recovery was not occurring at high rates due to ongoing contamination The exceeding level (EL) revealed that sediments in this study were considerably polluted by $\mathrm{Cu}, \mathrm{Zn}, \mathrm{Cd}$ and $\mathrm{Pb}$ and moderately polluted by other metals. This study suggested that chemical fractionation of sediments should be considered to provide more accurate appraisal of the availability and risk of heavy metals in the harbor.

\section{ACKNOWLEDGEMENTS}

The authors thank the financial support of NSERC and Concordia University for this study and the assistance of the yacht club manager during sampling.

\section{REFERENCES}

1) Apitz, S.E., Davis, J.W., Finkelstein, K., Hohreiter, D.L., Hoke, R., Jensen, R.H., Kirtay, V.J., Jersac, J., Mack, E.E., Magar, V., Moore, D., Reible, D., and Stahl, R. (2005). Assessing and managing contaminated sediments: Part I: Developing an effective investigation and risk evaluation strategy. Integrated Environmental Assessment and Management. 1, 2-8.

2) ASTM (1998). Standard Guide for Remediation of Groundwater by Natural Attenuation at Petroleum Release Sites. ASTM Designation E1943-98.

3) Banta, G., and Andersen, O. (2003), "Bioturbation and the Fate of Sediment Pollutants-Experimental Case Studies of Selected Infauna Species," Vie et Mileu. 53, 233-248

4) Boyd, R.S. (2010). Heavy metal pollutants and chemical ecology: Exploring new frontiers. Journal of Chemical. Ecology, 36, 46-58. https://doi.org/10.1007/s10886-0099730-5

5) Cardenas, M., Gailani, J., Ziegler, C.K. and Lick, W. (1995). Sediment transport in the Lower Saginaw River. Marine and 
and Freshwater Research. 46, 337-347.

6) Cardenas, M., and Lick, W. (1996) Modeling the Transport of Sediments and Hydrophobic Contaminants in the Lower Saginaw River, Journal of Great Lakes Research. 22 669682.

7) Darby, D. A., Adams, D. D., and Nivens, W. T. (1996), "Early Sediment Changes and Element Mobilization in a Man-Made Estuary Marsh," Sediment and Water Interactions, edited by P. G. Sly, Springer, Berlin, 343-351.

8) Environment Canada and Ministère du Développement Durable, de l'Environnement et des Parcs du Québec., (2007): Criteria for the Assessment of Sediment Quality in Quebec and Application Frameworks: Prevention, Dredging and Remediation, 39 pages.

9) Environment Canada. (1993): Sediment contamination in Montreal harbour; overview and remediation proposals, Minister of Supply and Service Canada.

10) Khan, M.S., Zaidi, A., Goel, R., and Musarrat, J. (2011). Biomanagement of Metal-Contaminated Soils. Springer.

11) Li, X., Shen, Z., Wai, O.W.H., and Li, Y.S., (2000). Chemical partitioning of heavy metal contaminants in sediments of the Pearl River Estuary. Chemical. Speciation and Bioavailability, 12, 17-25. https://doi.org/10.3184/095422900782775607

12) Lin, D., Cho, Y-M., Oen, A., Eek, E., Tommerdahl, J.P., Luthy, R.G. (2017) Toolset for assessment of natural recovery from legacy contaminated sediment: Case study of Pallanza Bay, Lake Maggiore, Italy, Water Research 121, 109-119. http://dx.doi.org/10.1016/j.watres.2017.05.024

13) Long, E.R., Field, L.J., and MacDonald, D.D., (1998). Predicting Toxicity in Marine Sediments with Numerical Sediment Quality Guidelines. Environmental and Toxicological. Chemistry 17, 714-727. https://doi.org/10.1002/etc.5620170428

14) Magar, V.S., Davis, J., Dekker, T. Erickson, M., Matey, D., Patmont, C., Swindoll, M., Brenner, R. and Zeller, C. (2004) Characterization of fate and transport processes: Comparing contaminant recovery with biological endpoint trends. Working draft, RTDF, Sediment Remediation Action Team.

15) Mulligan, C.N., Fukue, M. and Sato, Y. (2010) Sediments Contamination and Sustainable Remediation, CRC Press, Boca Raton.

16) National Research Council [NRC] (1999) National Symposium on Contaminated Sediments, Coupling Risk
Reduction and Sustainable Management and Reuse. Proceedings of a Conference May 27-29, 1998, Washington, DC, National Academy Press, Washington.

17) National Research Council. [NRC] (2007). Sediment dredging at Superfund megasites: Assessing the effectiveness. National Academies Press, Washington DC., $236 \mathrm{pp}$

18) Peng, J., Song, Y., Yuan, P., Cui, X., and Qiu, G., (2009). The remediation of heavy metals contaminated sediment. Journal of Hazardous Materials, 161, 633-640. https://doi.org/10.1016/j.jhazmat.2008.04.061

19) Pourabadehei, M., Mulligan, C.N., (2016a). Effect of the resuspension technique on distribution of the heavy metals in sediment and suspended particulate matter. Chemosphere, $153,58-67$.

https://doi.org/10.1016/j.chemosphere.2016.03.026

20) Pourabadehei, M., and Mulligan, C.N., (2016b). Selection of an appropriate masnagement strategy for contaminated sediment : A case study at a shallow contaminated harbour in Quebec , Canada. Environmental Pollution. 219, 846-857 https://doi.org/10.1016/j.envpol.2016.08.012

21) Pourabadehei, M., and Mulligan, C.N., (2016c). Geochemical and physical characteristics of contaminated sediment in a harbour area. 15th Asian Reg. Conf. Soil Mech. Geotech. Eng. 1893-1898.

22) Reible, D. (2006) Natural attenuation of contaminated sediments, Sediment Remedies: Monitored Natural Recovery - Technical Considerations for Evaluation and Implementation, U.S. EPA, Office of Superfund Remediation and Technology Innovation, Oct. October 30, 2006, Internet Seminar, http://www.cluin.org/conf/tio/sedmnr_103006/

23) USEPA (1995). Cleaning up contaminated sediments: A citizen's guide. Assessment and remediation of contaminated sediment (ARCS) program. U.S. Environmental Protection Agency. Great Lakes National Program Office, Chicago, IL EPA 905/K-95/001, July.

24) USEPA (2005), Contaminated Sediment Remediation Guidance for Hazardous Waste Sites EPA540-R-05-012, Office of Solid Waste and Emergency Response, December 2005.

25) Yong, R.N. and Mulligan C.N. (2019) Natural and Enhanced Natural Attenuation of Contaminants in Soils, $2^{\text {nd }}$ Ed, CRC Press, Boca Raton. 